\title{
The Role of a Diced Inverted Y Shaped Spreader Graft to Enhance Function in Open Rhinoplasty. A Novel Technique
}

\author{
AHMED F. EL-SHERIF, M.D. and IBRAHIM KAMEL, M.D. \\ The Department of Plastic \& Reconstructive Surgery, Faculty of Medicine, Ain Shams University
}

\begin{abstract}
Abstract: The role of spreader grafts in open rhinoplasty is at times mandatory. Various studies have shown that spreader grafts mot only support nasal function by maintaining the nasal valve support, but also restore nasal dorsum aesthetics and camouflage minor dorsal nasal deviations. This study was aimed to evaluate a surgical modification of the spreader graft to augment the aesthetic and functional outcomes in open rhinoplasty.
\end{abstract}

Patients and Methods: 24 patients (21 females, 3 males), who were candidates for open septo-rhinoplasty, were divided into two groups of 12 each. Group A traditional spreader grafts were applied, while in Group B, the modified diced inverted $\mathrm{Y}$ shaped spreader graft was used. Clinical assessments aided with photography were done at 3,6 and 12 months postoperatively together with CT-scan (6 months), and subjective questionnaires to assess the aesthetic and functional end results.

Results: The pre-and post-operative calculations made for the minimal cross sectional area at internal valve level using CT-scan showed there was mild significant changes in Group A more than the Group B ( $p$-values=0.0010). In the Group A, there was an increase in the minimal cross sectional area at the level of the internal valve by more in Group A by $+0.023 \mathrm{~cm}^{2}$, while in Group B it was $+0.019 \mathrm{~cm}^{2}$, respectively.

The patient satisfaction of the aesthetic results it was highest (86\%) in Group A, but high (57\%) in Group B. In addition, the procedure also clinically revealed a significant improvement in nasal obstruction in Group A (71\%) and improvement in Group B (43\%).

Therefore, there was improvement of functional outcomes if spreader graft was used, with more aesthetic improvement if modified spreader graft is used.

Conclucion: Modified spreader graft is an applicable, simple technical modification in spreader graft that could improve the aesthetic and functional outcomes in open septorhinoplasty.

Key Words: Spreader graft - Internal nasal valve - Nasal obstruction - Septo-rhinoplasty.

\section{INTRODUCTION}

The upper lateral cartilages usually form a $10-15^{\circ}$ angle with the cartilaginous septum. This area forms the critical internal nasal valve, which accounts for nearly $50 \%$ of nasal airway resistance. The average cross-sectional area at this level ranges between 0.71 to $0.74 \mathrm{~cm}^{2}$ [1].

If the upper lateral cartilage is inherently weak or its position has been altered (surgically or from congenital deviation of the dorsal septum or previous trauma), the middle nasal vault may collapse at rest or forced breathing leading to worsening of nasal obstruction [2]. Nasal obstruction due to internal nasal valve collapse is not uncommon [3].

The role of spreader grafts and its importance in open rhinoplasty cannot be underestimated. Various studies have shown that spreader grafts play a valuable role in the support of the nasal valve, restoration of dorsal nasal aesthetics, and maintain the straightened position of minimally deviated cartilaginous septal dorsum [4].

In 1984, Sheen originally described spreader grafts to target a dysfunctional internal nasal valve with or without middle vault asymmetry and/or narrowing. These grafts were placed in a submucoperichondrial pocket during the closed approach [5]. However, evolution of open rhinoplasty techniques have refined spreader graft placement position and expanded indications for its use.

In addition, spreader grafts are beneficial not only in reconstructing the middle one-third of the nose but also in supporting the collapsed and/or deviated nasal vault $[6,7]$.

There are many modifications in shape, size, and source of Spreader Grafts. Three of these modifications are well-known, which are Traditional, through-and-through, Pull up, Butterfly, Extended Spreader grafts and Spreader Flap [8,9].

This study describes a technical modification in spreader graft application. This modification was evaluated by its effect on the Internal Nasal Valve (INV) area, by measuring minimal cross- 
sectional area using Computed Tomography (CT) scan, and the aesthetic outcome backed up by photography.

\section{PATIENTS AND METHODS}

This study was conducted from 2014 till 2017 and included 24 patients ( 21 females, 3 males), with an age range of 18 to 37 years. All of them complained of humpy nose, nasal obstruction with or without deviated septum.

\section{Patients were divided into 2 groups (Fig. 1):}

Group A: Included 12 patients who were candidates for rhinoplasty with the modified Spreader Graft.

Group B: Included 12 patients who were candidates for rhinoplasty with Traditional Spreader Graft.
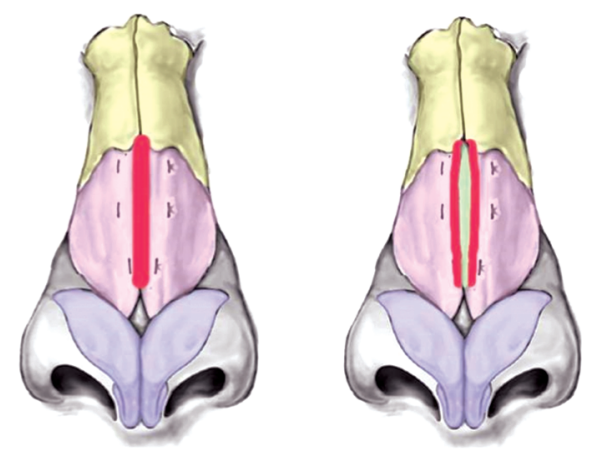

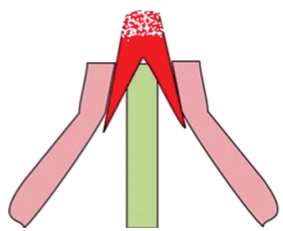

Group A

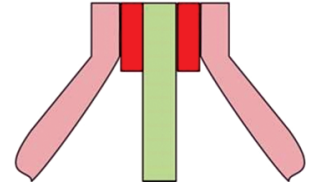

Group B
- Group A with modified diced spreader graft - Group B with traditional spreader graft

Fig. (1): Classification of groups according to applied type of spreader graft.
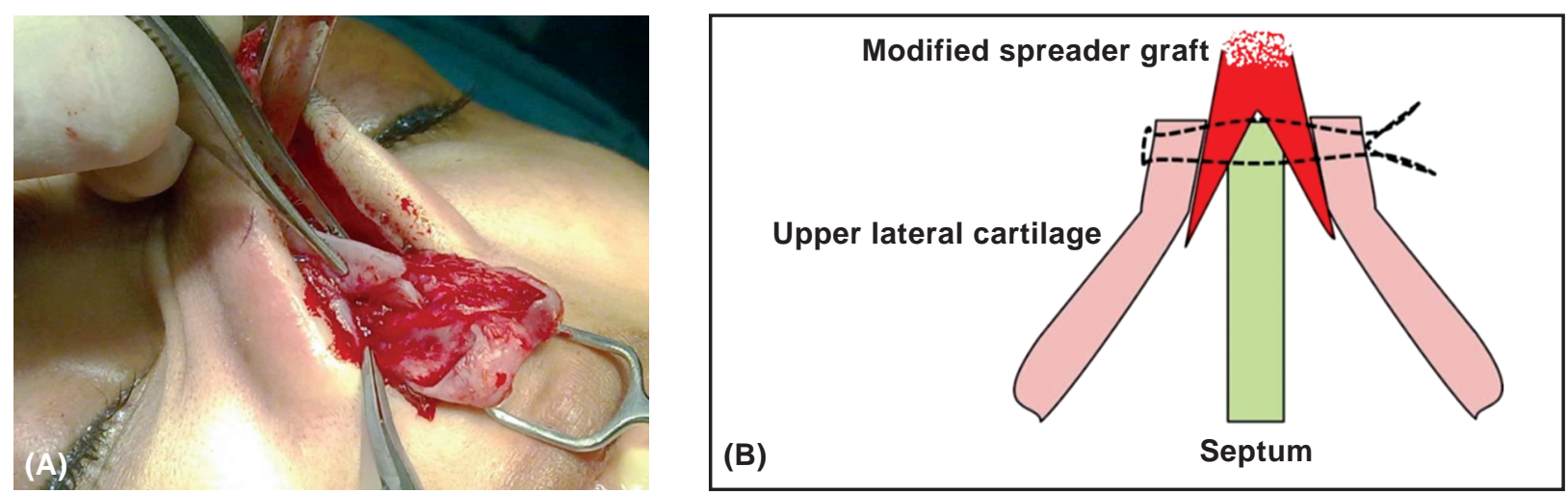

Fig. (3): (A left) Fixation of the modified spreader graft over the nasal septum - (B right) Diagram of the umbrella position of the modified spreader graft over the septum and transfix suturing using non-absorbable propylene $4 / 0$.

\section{Pre-operative clinical evaluation:}

Pre-operative clinical examination, photography and CT-scan for calculation of the minimal cross sectional area of internal nasal valve were done for every patient using Image J 1.38e/Java 1.5.0_09 software.

Technique of Rhinoplasty with modification of the spreader graft (Figs. 2, 3A,B):

All patients were operated upon using open septo-rhinoplasty technique. After reducing the cartilaginous hump, a nasal septal graft was used as source the of spreader graft.

Partial longitudinal splitting of the harvested cartilaginous graft was performed in vitro Fig. (2). The graft was then fixed over the cephalic part of the cartilaginous septum simulating "the umbrella graft", and forcing a space between the septum and the upper lateral cartilages Fig. (3A). The modified spreader graft is fixed by transfixing sutures to the upper lateral cartilages by non-absorbable prolene 4/0 or 5/0 Fig. (3B). After fixation was achieved, a crushing artery was used to dice the superior part of the graft, avoiding an unnecessary surgically created evident dorsal nasal hump.

Middle and/or inferior turbenectomy were done in five patients. All patients had internal nasal pack and external nasal splint for 6 days.

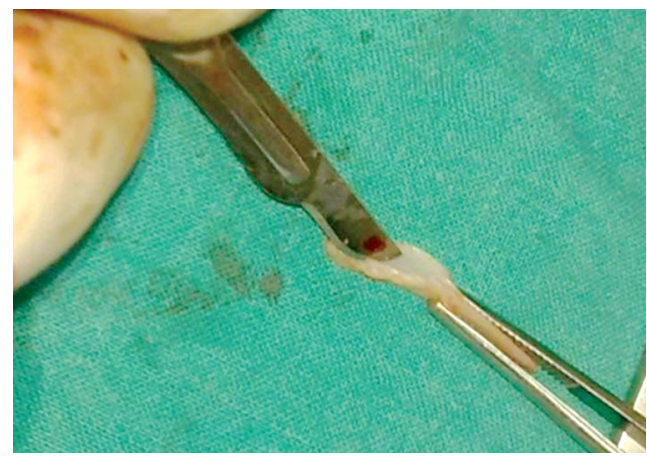

Fig. (2): Partial longitudinal splitting of the graft. 


\section{Post-operative assessment:}

Post-operative assessments were done at 3, 6, and 12 and months by photography. At the $6^{\text {th }}$ month follow-up visit, all patients were asked to do CT-scan and they were evaluated with standardized questionnaire. Participants were questioned to evaluate improvement in their nasal airway and the aesthetic outcomes on 3-point scale. [Score: $\operatorname{Bad}=-1$, Fair $=0$, Good $=1]$.

Statistical analysis of results was done by software MedCalc ${ }^{\circledR}$ Version 9.6.2.0 Copyright $(\odot)$ 19932008. Pearson's correlation coefficient test was used for comparisons of paired data. A value of $p$ value $<0.05$ was considered significant.

\section{RESULTS}

This study included 21 females, 3 males, their age was $28 \pm 2.1$ years. All of them complained of humpy nose, nasal obstruction, and three cases had deviated septum.

Based upon pre-and post-operative calculations made for the minimal cross sectional area at internal valve level using CT-scan (Table 1), there was

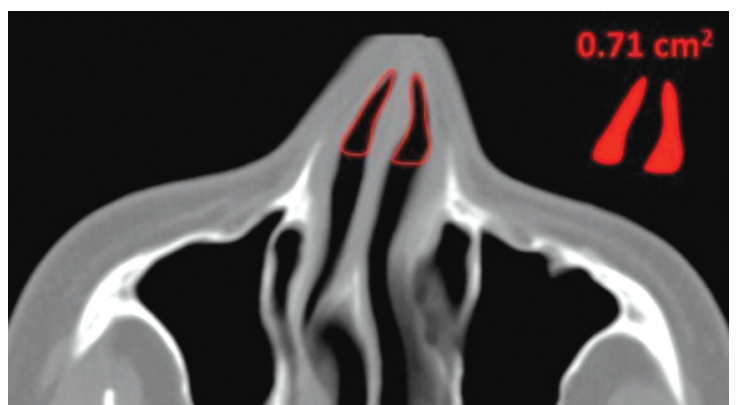

Pre-operative significant improvement in both groups but more in Group A ( $p$-values respectively 0.4315 and $0.2123)$.

In Group A, there was an increase by +0.023 $\mathrm{cm}^{2},+0.019 \mathrm{~cm}^{2}$ respectively (Figs. 4,5 ).

By analysis of the objective scoring system, as regard the patient satisfaction of the aesthetic results it was highest (84\%) in Group A, and high (59\%) in Group B. In addition, as regard the nasal obstruction, it revealed a significant improvement in group (72\%) compared to improvement in Group B (44\%).

Table (1): Minimal cross sectional area at internal valve level using CT-scan and the differences between preoperative and $6^{\text {th }}$ months post-operative average values. $\left(\right.$ Normal $\left.=0.71-0.74 \mathrm{~cm}^{2}\right)$.

\begin{tabular}{lll}
\hline Group & \multicolumn{1}{c}{ A } & \multicolumn{1}{c}{ B } \\
\hline Means & $0.70 \mathrm{~cm}^{2}-0.72 \mathrm{~cm}^{2}$ & $0.70 \mathrm{~cm}^{2}-0.72 \mathrm{~cm}^{2}$ \\
Differences & $+0.023 \mathrm{~cm}^{2}$ & $+0.019 \mathrm{~cm}^{2}$ \\
$p$-value & 0.0009 & 0.0211 \\
\hline
\end{tabular}

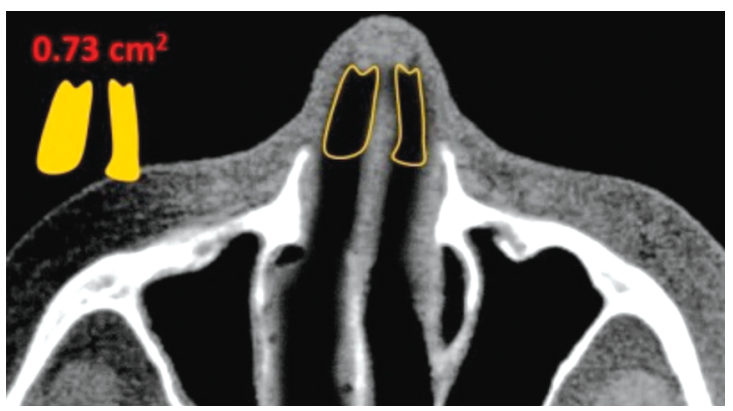

$6^{\text {th }}$ months

Post-operative

Fig. (4): Calculation of minimal cross sectional area at internal valve level CT-scan of a case in (Group B) (pre-op. $=0.71 \mathrm{~cm}^{2}$, post-op. $=0.73 \mathrm{~cm}^{2}$ ).

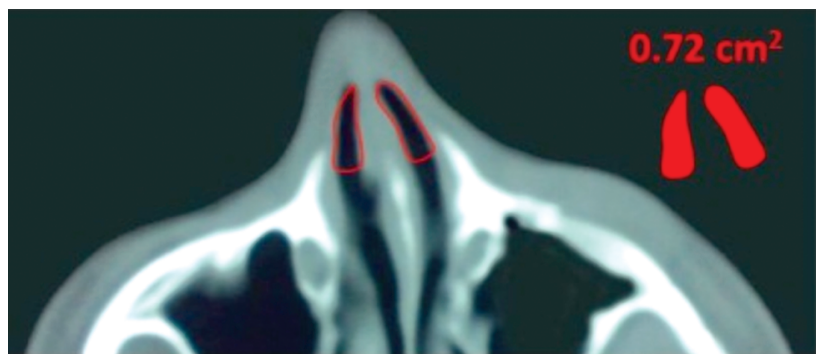

Pre-operative

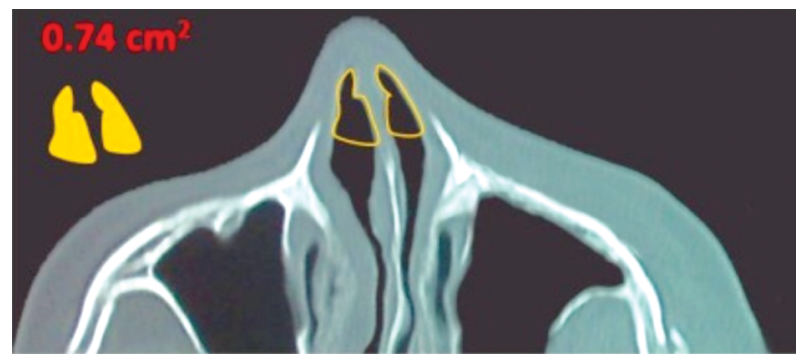

$6^{\text {th }}$ months

Post-operative

Fig. (5): Calculation of minimal cross sectional area at internal valve level CT-scan of a case in Group A $\left(\right.$ pre-op. $=0.72 \mathrm{~cm}^{2}$, post-op. $\left.=0.74 \mathrm{~cm}^{2}\right)$ 

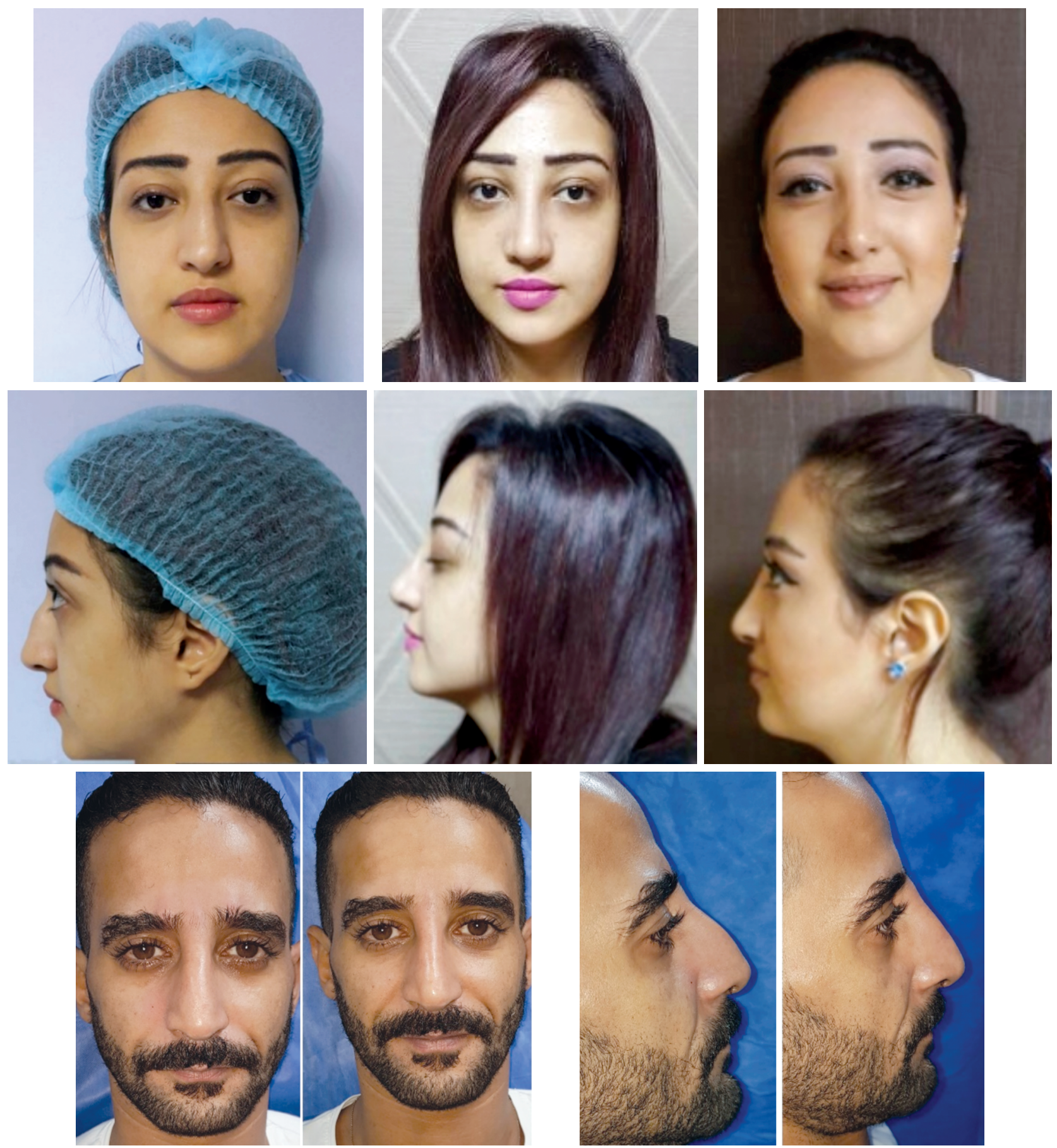

Fig. (6): Pre, 1 and 6 months post-operative (Group A).

\section{DISCUSSION}

Excessive dorsal nasal hump reduction may alter the internal nasal valve in a considerable percentage of patients, thus leading to nasal obstruction post-operatively, unless managed, preferably intra-operatively [10]. Proper placement of the spreader graft under the caudal aspect of the bony vault with extension towards the tip, parallel to the dorsal margin of the septum and medial aspect of the upper lateral cartilage prevents the post-operative internal nasal valve collapse [9].
Correction of a crooked or deviated nasal septum is a complex cosmetic and functional issue. Although corrections using a wide range of surgical techniques to straighten the nose and maximize nasal function have been proposed, recurrence may be common due to cartilage memory and scar contracture. Therefore, to prevent recurrence and maintain the correction of the septum, a permanent support that is stable and strong with the ability to maintain its given shape after placement on one or both sides of the septum is mandatory [11]. 
In this study, the technical modification of the spreader graft was evaluated to gain the benefits of the spreader graft application with minimizing its complications.

The application of spreader graft is applied for aesthetic and reconstructive indications after correction of humpy nose and deviated nasal septum. Dorsal nasal hump reduction without application of spreader graft may lead to significant postoperative nasal obstruction.

The graft, placed within the precise pocket is secured using $5 / 0$ prolene mattress suture, transfixing the graft to avoid its migration.

Adequate assessment of internal nasal valve dysfunction and indications for spreader graft placement most often can be made on physical examination alone. Many studies have reported the utility of rhino-manometric analysis for nasal obstruction, including internal valve abnormalities $[4,7,12]$. However, rhino-manometry helps to evaluate resistance to airflow but does not provide accurate information about the location of the obstruction [13,14].

Acoustic rhinometry is a newer technique that is helpful in evaluating the cross-sectional area of the nose and localizing the site of obstruction. However, much debate still exists regarding the relative inconsistencies between subjective complaints of obstruction and objective measurements and readings [12].

The most important variable remains the patient's own assessment of whether nasal breathing has improved following spreader graft placement or not [15].

In this study, the authors used CT-scan as a method to calculate the minimal cross section at the level of internal nasal valve pre-and postoperatively as a simple, applicable and accurate method.

Traditional spreader grafts may result in unpleased functional and aesthetic outcomes. The functional complications "nasal obstruction" usually occurs if the grafts at the internal nasal valve are not positioned and stabilized properly. The aesthetic problem associated with spreader graft placement includes the potential to create broadness and/or asymmetry of the middle nasal vault. In addition, contour irregularities may be seen along the dorsum. This brought to our attention the idea of dicing the upper dorsal part of the graft, which dramatically improved the results.
By analysis of the minimal cross sectional area at internal valve level, there was significant improvement in Group A ( $p$-value $<0.05)$ more than Group B, that reveals the importance of spreader graft to reconstruct the internal nasal valve with reductive septo-rhinoplasty.

The differences in average of the minimal cross sectional area at internal valve level between preoperative and post-operative measurements in both groups were increase by $+0.023 \mathrm{~cm}^{2}$ and $+0.019 \mathrm{~cm}^{2}$ respectively, that reveals more slight widening after application of the modified spreader graft.

These results were approved subjectively by improvement of the nasal obstruction. As regard the patient satisfaction of the aesthetic results it was higher (86\%) in Group A than Group B (57\%). This could be due to the potential broadness or contour irregularities of the middle nasal vault that may occurred with application of traditional spreader graft. The application of anatomical shaped modified dicied spreader graft eliminates the possibility of neither dorsum broadness nor contour irregularity.

\section{Conclusion:}

With function and aesthetics objective linked in septo-rhinoplasty, there is a high satisfaction rates in nasal symmetry and appearance following diced modified spreader graft placement. With careful technique and regard to structural concerns, modified spreader grafts can predictably result in more aesthetic enhancement and functional improvement in most of patients.

\section{REFERENCES}

1- Chih W.T., Rong San J., Shan Hen W. and Chen Yi H.: Acoustic Rhinometry in Measuring Nasal Volumes. Mid. Taiwan J. Med., 8: 27-31, 2003.

2- Cole P., Chaban R., Naito K. and Oprysk D.: The obstructive nasal septum. Effect of simulated deviations on nasal airflow resistance. Arch. Otolaryngol. Head Neck Surg., Apr., 114 (4): 410-1, 1988.

3- Stacey D.H., Cook T.A. and Marcus B.C.: Correction of internal nasal valve stenosis: A single surgeon comparison of butterfly versus traditional spreader grafts. Ann. Plast. Surg., 63 (3): 280-4, 2009.

4- Teymoortash A., Fasunla J.A. and Sazgar A.A.: The value of spreader grafts in rhinoplasty: A critical review. Eur. Arch. Otorhinolaryngol., 269 (5): 1411-6, 2012.

5- Sheen J.H.: Spreader graft: A method of reconstructing the roof of the middle nasal vault following rhinoplasty. Plast. Reconstr. Surg. Feb., 73 (2): 230-9, 1984.

6- Inanlı S., Serin G.M., Polat S. and Aksoy E.D.: Placement technique of extended spreader grafts. Kulak Burun Bogaz Ihtis Derg., 21 (6): 333-7, 2011. 
7- Mendelsohn M.: Straightening the crooked middle third of the nose: Using porous polyethylene extended spreader grafts. Arch. Facial Plast. Surg. Mar.-Apr., 7 (2): 74-80, 2005.

8- Gunter J.P. and Rohrich R.J.: Correction of the pinched nasal tip with alar spreader grafts. Plast. Reconstr. Surg., Nov., 90 (5): 821-9, 1992.

9- Wagner W. and Schraven S.P.: Spreader grafts in septorhinoplasty. Laryngorhinootologie, 90 (5): 264-74, 2011.

10- Ozmen S., Ayhan S., Findikcioglu K., Kandal S. and Atabay K.: Upper lateral cartilage fold-in flap: A combined spreader and/or splay graft effect without cartilage grafts. Ann. Plast. Surg., 61 (5): 527-32, 2008.

11- Emsen I.M.: A different approach to the reconstruction of the stubborn crooked nose with a different spreader graft: Nasal bone grafts harvested from the removed nasal hump. Aesthetic Plast. Surg., 32 (2): 266-73, 2008.

12- De Pochat V.D., Alonso N., Mendes R.R., Cunha M.S and Menezes J.V.: Nasal patency after open rhinoplasty with spreader grafts. J. Plast. Reconstr. Aesthet. Surg., Jun., 65 (6): 732-8, 2012.

13- John M.H., Patrick B. and Deborah W.: Spreader Grafts Rhinoplasty. http://emedicine.medscape.com/article/ 1292527. Updated: Jan. 31, 2012.

14- Byrd H.S., Salomon J. and Flood J.: Correction of the crooked nose. Plast. Reconstr. Surg. Nov., 102 (6): 214857.D, 1998 .

15- McCaffrey T.V.: Nasal function and evaluation. In: Bailey B. Head and Neck Surgery- Otolaryngology. Vol. 1. Philadelphia, Pa: JB Lippincott, 262-8, 1993. 